\title{
Eye and its health from the viewpoint of Traditional Iranian Medicine
}

\author{
Review Article
}

\section{Jamshid Shayanfar ${ }^{1}$, Hassan Ghasemi ${ }^{2}$, Seyed Saeed Esmaili ${ }^{3}$, Fatemeh Alijaniha ${ }^{4}$, Ali Davati ${ }^{*}$}

1. Department of Iranian Traditional Medicine, School of Medicine, Shahed University, Tehran, Iran

2. Department of Ophthalmology, Shahed University, Tehran, Iran

3. Department of Traditional Medicine, School of Medicine, Shahed University, Tehran, Iran

4. Traditional Medicine Clinical Trial Research Center, Shahed University, Tehran, Iran

5. Department of Social Medicine, School of Medicine, Shahed University, Tehran, Iran

\begin{abstract}
Background: Traditional Iranian Medicine (TIM) pays special attention to the prevention of diseases rather than their treatment. The six considerations of maintaining health and prevention from diseases are also apply to the eye in TIM. Objective: This study aims to assess the relationship between essential lifestyle and eye health and preventive factors of ocular diseases in TIM. Methods: In this library-based study, primarily the standpoints of ancient Iranian physicians on the effect of lifestyle concerning the eye health were extracted from 4 sources including Al-Qanun fi at-Teb, Al-Havi fi at-Teb, AL-mujaz fi at-Teb and Akbari's Teb about food and drinks, climatic conditions and environment, physical activities and rest, sleep and wakefulness, evacuation and retention, and psychological states; Then some of these factors were compared to new literature. Diseases of other organs effective on ocular health were also investigated. The findings were compared with modern medicine in medical literature such as PubMed and Google Scholar databases. Results: Some of the most effective factors on the eye health from the TIM point of view are foods and drinks, sleep, weather conditions, paying attention to evacuation and retention, psychological conditions, physical activities and rest and also stomach health. Conclusion: Correct lifestyle and improving the general health play important role in eye health. Lifestyle modification decrease the risk of developing near-sightedness, age-related macular degeneration, glaucoma, and cataract. More clinical studies should be performed to collaborate the role of all components of the six principles of health maintenance on eye
\end{abstract}

Keywords: Eye health, Traditional Iranian Medicine, Eyesight, Lifestyle.

\section{Introduction}

The eyes from TIM point of view are noble members of the body in which there are numerous nerves, arteries, and veins. An eye is comprised of seven stages and 3 layers and has hot and wet temperament. The indicator of the hot temperament of the eye is its fast movements, distinct veins, its reddish color and hotness to touch. The indicators of the wet temperament of the eye are its leakages and tearing. (1)

The health condition of the eye can be determined through examining by touch (to investigate the hotness or coldness and stiffness or softness), eye movements (to investigate the increase or decrease of the movements), observation of the eye vessels (to see if they are filled or empty or if they are distinct and clear), the color of the eye (redness, yellowness, whiteness, or blackness), eye function (eyesight), the amount of eye secretions (the increase or decrease of

*Corresponding Author:

\section{Ali Davati,}

Department of Social Medicine,

School of Medicine, Shahed University,

Tehran, Iran.

E-mail: a-davati@yahoo.com the tears), and being affected by hotness or coldness.(2)

Eye diseases can either originate from the eye itself or are developed by the contribution of other parts of the body. Brain and stomach have the most mutual effects on the eye diseases.

From the ancient Iranian physicians' point of view, eye is a sub-part of the brain and the brain temperament and health can be determined through eye's states. Some of the most important brain indicators resulting from the eyes are the vessels, color, feeling heavy or light and the local touch and eye secretions (see Table 1). (3)

Table 1. Brain Indicators Resulting from the Eyes

\begin{tabular}{|l|l|}
\hline \multicolumn{1}{|c|}{ Eye condition } & \multicolumn{1}{c|}{ Indication } \\
\hline Eye dryness & Dry temperament of the brain \\
\hline Big eye vessels & Hot temperament of the brain \\
\hline Eye secretions & $\begin{array}{l}\text { Wet temperament of the brain/ } \\
\text { extreme reduction of the power }\end{array}$ \\
\hline Blinking a lot & Hotness of the brain/madness \\
\hline Eye redness and hot touch & Hot and wet brain \\
\hline Small and indented eyes & $\begin{array}{l}\text { Decrease too much of the brain } \\
\text { mass }\end{array}$ \\
\hline $\begin{array}{l}\text { Lack of redness in the eye } \\
\text { with narrow vessels and } \\
\text { hot touch }\end{array}$ & Dry temperament of the brain \\
\hline
\end{tabular}


International Journal of Ayurvedic Medicine, 2019, 10(1), 7-13

\begin{tabular}{|c|c|}
\hline Eye condition & Indication \\
\hline $\begin{array}{l}\text { Protrusion of the } \\
\text { eyes }\end{array}$ & Swelling of the brain \\
\hline $\begin{array}{lr}\text { Sapphire } & \text { eye, } \\
\text { normal eye touch, } \\
\text { and } \\
\text { senses }\end{array}$ & Wet temperament of the brain \\
\hline
\end{tabular}

In the treatment of diseases, the TIM physicians at the first stage, insisted on maintaining health and at the next stage treated the disease. Based on this concept, practical medicine is categorized into two parts of maintaining wellness and the treatment of the diseases. Rabi ibn Ahmad Akhaveini in "hedayat AL-motaalemin fi AL-Teb", (the first medicinal book in Persian) has stated:

"Medicine is a profession which preserves humankind's health and if the health is lost the medical practitioner regains it by knowledge and action." (4)

In other words, prevention is more important than treatment and health maintenance is so important that the TIM believes the role of the medical practitioner is to maintain health at the time of well-being and to restore it at the time of disease. (5)

The basics of health maintenance which are known as the six principles include foods and drinks, climatic conditions and environment, physical activities and rest, sleep and wakefulness, evacuation and retention, and psychological states. (6)

Eye disorders are one of the most important problems of general health which imposes huge costs to the health system. Despite the reduction of eye disorders in the last two decades, they are still one of the main health concerns in some parts of the world. (7)

Visual impairment is the third dysfunction in the patients older than 70, after cardiovascular diseases and arthritis. (8)

Cataract, age-related macular degeneration (ARMD), uncorrected refractive errors, glaucoma, and corneal opacity are the most important causes of visual impairment and many of them are preventable or treatable. $(9,10)$

As the age increases, the occurrence of eye disorders increases and the risks of these disorders are higher among women compared to men. (11)

In a study conducted in the United States in 2013, the economic cost of the treatment of visual impairment was estimated at 51.4 billion dollars. (12)

The treatment in the Traditional Iranian Medicine is based on four principles:

Modification of the six principles of health maintenance

Diet therapy

Pharmacotherapy

Physical treatments like surgery (6)

Non-medicinal treatments such as lifestyle modification play an important role in reducing symptoms or improving the prognosis of many diseases such as cardiovascular disorders, on their own or along with other new treatments using drugs or surgery. (13)

The concepts discussed in this study are collected and presented based on the opinions of TIM physicians extracted from four mentioned Iranian Traditional books and finally the basics of eye health have been presented based on the six mentioned health principle.

\section{Materials and method}

This research is a library-based study and review. The concepts discussed in this study are collected and presented based on the opinions of Traditional Iranian Medicine physicians extracted from four books including Al-Qanun fi at-Teb by Ibn Sina, Al-Havi fi at -Teb by Muhammad ibn Zakariya al-Razi, AL-mojaz fi at-Teb by Ibn Nafis and Akbari's Teb by Muhammad Akbar Arzani. Finally the basics of eye health have been presented based on the six mentioned principles. To compare these concepts about the effects of lifestyle on eye health with the viewpoints of modern medicine, The Eyesight was searched with Lifestyle, Sleep, Nutrition, Exercise, Weather, Emotional and Psychological states, Evacuation and Retention and eye, in PubMed and Google Scholar databases.

\section{Results}

Like the general principles of health maintenance in TIM, following the principles of health maintenance related to eyes and avoiding harmful cases is essential. The six effective principles of eye health maintenance in the TIM to prevent vision impairment are:

Foods and drinks: Avoidance of excessive drinking alcohol, avoidance of concentrated and massy foods and drinks, avoidance of anything that causes excessive dryness such as too much salt, avoidance of anything that makes too much vapor such as lentils and cabbage, avoidance of overeating.

Weather conditions: Avoidance of smoke and steam, avoidance of out of moderation weather (very hot or cold), and dusty and poisonous winds are essential for eye health.

Physical Activities and Rest: Avoidance of reading very small size transcripts and watching very tiny objects except when doing eye exercises. Eye exercises are beneficial if done moderately. And avoidance of continuous gaze to a single object.

Sleep and Wakefulness: Avoidance of long or short sleeping and wakefulness and avoidance of sleeping immediately after eating food.

Evacuation and Retention: Avoidance of severe vomiting which moves substances towards the brain (if vomiting is necessary it's better to be mild and after eating), successive bloodletting and hijama, too much crying and excessive intercourse.

Psychological states: Since eye is a sub-part of brain, the diseases and conditions that affect the health of the brain such as emotional and psychological states 
affect the eye health too.

Other inappropriate and harmful conditions and foods to eye and eyesight: position.

Excessive bathing, and sleep in the supine

Vegetables such as garlic, onion, chives, ripe olives, dill, cabbage and lentils. (3)

Eating too much sweets, eating foods that are hard to digest, headache-inducing foods, sexual stimulants and eating spicy and melancholy inducing foods. (14)
Eating different foods in tandem, looking at very light and shiny objects, looking at white things like snow. (15)

\section{Eye health points}

Pouring fennel juice in the eyes at any time, pouring sweet or sweet and sour pomegranate juice in the eyes, opening eyes in the water makes them clear and sharp. (3)

Other useful vegetables and plants for eye and vision enhancement based on two other important references in TIM are seen in Table 2. $(16,17)$.

Table 2. Useful Herbs for Eye Health in Makhzan al-Adwiya \& Al-Shamil Fi al-Sana'at al-tebiyah

\begin{tabular}{|c|l|l|l|}
\hline Sr. No & Scientific name & Traditional name & Reference Book \\
\hline 1 & Thymus vulgaris & Satar & Makhzan al-Adwiya \\
\hline 2 & Prunus domestica L. & Ejas & Makhzan al-Adwiya \\
\hline 3 & Thymus capitatus & Hasha & Makhzan al-Adwiya \\
\hline 4 & Origanum majorana L. & Marzanjush & Makhzan al-Adwiya \\
\hline 5 & Ruta graveolens L. & Sodab & Makhzan al-Adwiya \\
\hline 6 & Foeniculum vulgare L. & Razianaj & Makhzan al-Adwiya \\
\hline 7 & Cinnamomum zeylanicum & Darsini & Makhzan al-Adwiya \\
\hline 8 & Rheum ribes L. & Ribas & Makhzan al-Adwiya \\
\hline 9 & Vigna radiata R.wilczek & Mash & Makhzan al-Adwiya \\
\hline 10 & Rhus coriaria L. & Somagh & Makhzan al-Adwiya \\
\hline 11 & Berberis vulgari L. & Anbarbaris & Al-Shamil Fi al-Sana'at al-tebiyah \\
\hline 12 & Beta vulgaris L. & Selgh & Al-Shamil Fi al-Sana'at al-tebiyah \\
\hline 13 & Zingiber officinale roscore & Zanjebil & Al-Shamil Fi al-Sana'at al-tebiyah \\
\hline 14 & Citrus medica var.cedrata & Otroj & Al-Shamil Fi al-Sana'at al-tebiyah \\
\hline
\end{tabular}

Also eyes are one of the parts of the body that can be affected by stomach diseases. Dysfunction of the stomach can lead to some eye diseases. In such cases, the function of the stomach should be regulated and modified at first otherwise no suitable outcome would be obtained. For instance, according to Rhazes' opinion, constipation is one of the problems that must be treated first in all types of eye diseases regardless of their cause. (18)

\section{Discussion}

Lifestyle modification, especially with regards to the principles of nutrition, has widened the horizons for researchers in a variety of diseases, including eye disorders.

For instance, lifestyle can be effective in the prevention or reduction of developing cataract, agerelated macular degeneration (ARMD), glaucoma, and diabetic retinopathy. (19)

The following issues are results of some studies about the effects of correct lifestyle on ocular health.

\section{Nutrition}

Raman et al. through reviewing literature showed that diets enriched by fruits and vegetables and vitamin $\mathrm{C}$ and $\mathrm{E}$ have a protective effect against cataract and ARMD, however, the risk of ARMD increases by taking too much vitamin $\mathrm{C}$ supplements. Also, eating too much meat would increase the risk of developing cataract and ARMD. Taking vitamin A and its derivatives in the diet has a protective effect against cataract but taking its supplements doesn't have the same effect. Taking vitamin A both in diet and as a supplement would have a protective effect against ARMD. There are no recorded evidence about the protective effects of consuming fruits and vegetables against glaucoma. (20)

In a study conducted by Bringman et al. the effect of salt on developing age-related macular degeneration was investigated. This study revealed that excessive salt intake can exacerbate age-related retinal diseases by triggering local inflammation and producing the angiogenic factor through increasing the plasma osmolality. Consuming high amounts of salt can also increase the risk of glaucoma and diabetic retinopathy by increasing blood pressure. Therefore, changing the consumption of water, salt, and minerals which control the renal secretion of salt can introduce nutritional 
approaches for the prevention of ARMD. (21)

The collected data from the previous studies conducted by Klein et al. showed that alcohol consumption can increase the risk of cataract occurrence in the individuals who drink four times or more each day compared to the individuals who don't drink alcohol. (22)

\section{Sleep}

To investigate sleep quality and stress, Ji et al. conducted a study on 134 patients suffering from central serous chorioretinopathy (CSCR). They demonstrated that the prevalence of unsuitable sleep quality in a one month period is higher in the patient group compared to the control group based on the Pittsburgh Sleep Quality Index (PSQI) questionnaire (58.2 against 23.9); Also stress was higher in the patient group compared to the control group (23.9 against 3\%), therefore unsuitable sleep quality and stress are the risk factors of CSCR. (23)

Li et al. conducted a study on 121 mice that were deprived of sleep for 10 days. They discovered that sleep deprivation causes a decrease in tear secretion, corneal sensitivity, and the dryness of the mice's eyes. Also, after 14 days of rest, all the changes observed in the eye surface went back to normal. (24)

\section{Exercise}

Hospital case-control studies on eye diseases in 258 patients suffering from retinal artery occlusion showed that the physical activity of the patient group was less than the control group. Also, extreme sports activities such as running a marathon can cause a central retinal vein thrombosis.

Retrospective and prospective studies also demonstrate that physical activity might decrease the occurrence of neovascular age-related macular degeneration.

In diabetic patients, regular physical activity also improves glucose transfer to the cells and insulin sensitivity and decreases blood glucose levels.

However, there is weak evidence supporting that regular physical activity, in the long run, can reduce the intraocular pressure but comparative studies have shown that the lack of exercise in the patients suffering from glaucoma is seen more frequently compared to the control group. (25)

Knudtson et al. conducted a study between the years of 1988 to 1990 with three follow-ups in 5-year intervals on 4926 patients aged 43 to 86 . In this study, the patients were asked about their physical activity. It was shown that in individuals with an active lifestyle (exercising more than 3 times a week with sweating) the incidence of ARMD, after 15 years, was 70 percent less than the people who had less activity (less than 3 times a week). Also, in people who had more daily walks the ARMD incidence was $30 \%$ less. Moreover, this study revealed that there is no relation between physical activity and early-onset ARMD incidence. (26)

A retrospective study was performed by Theofanus et al. in the years 2008 to 2013 on 60789 kids and teenagers aged 5 to 19 . It was shown that in participants who had at least 1 hour of daily exercise, the prevalence of near-sightedness was $10 \%$ less. It must be mentioned that the relationship between nearsightedness and exercise is independent of BMI. (27)

\section{Climatic conditions and environment}

Ettl et al. presented a report of edema of the cornea in 1992. In this report, a 23-year-old individual suffered from transient blurred vision after going on a tour to a cold area. This problem occurred 4 other times in similar cases and each time the blurred vision and corneal opacity was resolved one hour after returning home. The symptoms were intensified by skiing downhill and in windy weathers and low temperatures. (28)

The study conducted by Weale et al. revealed that heat can be a risk factor for primary open angle glaucoma. This claim is not merely true for the inhabitants of the African regions because in Bangladesh, which also has high-temperature weather, higher prevalence of primary open angle glaucoma (POAG) has been reported. On the other hand, Africans who migrated to mild-climate areas experience vascular system contraction to maintain heat which can be effective in delaying the onset of POAG and reducing its prevalence. (29)

West et al. revealed the strong relationship between indoor air pollution from biofuels (such as wood) and cataract incidence by investigating the previous studies. (30)

Arcelus et al. conducted a prospective study on the effect of smoking cigarettes on the incidence of glaucoma on 16797 participants who didn't have glaucoma at the beginning of the study and they were followed-up for 8.5 years. At the beginning of this study, the participants were asked about smoking cigarettes. They were asked about developing glaucoma every two years. In the 8.5 years of follow-up, 186 new cases of glaucoma were identified. The results showed that cigarette smokers had a higher risk of developing glaucoma and this risk was even higher in heavy smokers. This risk had a direct correlation with the number of smoked cigarettes. (31)

\section{Evacuation and retention}

$\mathrm{Qu}$ et al. conducted a study in China on 4656 participants aged 40 or higher. They found that constipation (passing stool less than 2 times a week) is a risk factor for POAG. (32)

Rubaie et al. reported a sudden painless loss of vision in the right eye of a 54-year-old man near counting fingers. After further Inquiring about intense activities it was revealed that the vision changes were 
more frequent immediately after sexual activity and finally he was diagnosed with Valsalva retinopathy after sexual activity. Sexual activity causes hormonal, hemodynamic and mechanical changes in the body. Regardless of the medical condition of the patient, these changes are considered as risk factors for Valsalva retinopathy. A significant increase in intravenous pressure in all of the body during Valsalva maneuver increases the risk of bleeding in all body parts including the retina. The relationship between sexual activity and bleeding in the retina is reported in other studies such as the study conducted by Freiberg et al. (33)

Therefore regarding to mentioned studies, considering correct lifestyle is beneficial in eye health maintenance and prevention of its diseases.

\section{Stress}

Carrim et al. conducted a study on 42 patients with acute anterior uveitis (AAU) and 25 controls for the duration of 12 months. The Social Readjustment Rating Questionnaire (SRRQ) and the General Health Questionnaire (GHQ) were completed by the participants. Follow-up after 3 months with those questionnaires showed that the patients suffering from
AAU reported more stress than the control group. This study demonstrated the role of stress in the recurrence of AAU. (34)

A study conducted by Yilmaz et al. on 1458 patients of whom 121 patients had dry eye disease (DED), showed that the risk of eye dryness is increased in depression, anxiety and or stress . (35)

\section{Other eye health points}

Hassan et al. revealed that cataract induced rabbits which were treated with ophthalmic drops of Foeniculum vulgare (fennel) extract for two weeks, had less corneal opacity score than the control group. Fennel has antioxidant effects and this effect is the probable reason for its protection against cataract. (36)

Kamal et al. showed that the rabbits which were fed with diet including $20 \%$ pomegranate had notable decline in intra ocular pressure in comparison to control group (glaucoma rabbits). There were also notable increase in reduced glutathione, and activity of Catalase and superoxide dismutase. (37)

The summary of TIM recommendations in accordance with modern medicine studies are seen in Table 3.

Table 3. Comparison of TIM Recommendations \& Recent Studies (Ref. No.) about Eye Health

\begin{tabular}{|c|c|c|c|}
\hline & & TIM recommendations & $\begin{array}{l}\text { Ref. no. of } \\
\text { evidences in } \\
\text { recent } \\
\text { studies }\end{array}$ \\
\hline \multirow{6}{*}{$\begin{array}{l}\text { Six principles } \\
\text { of health } \\
\text { maintenance }\end{array}$} & $\begin{array}{l}\text { Foods \& } \\
\text { drinks }\end{array}$ & $\begin{array}{l}\text { Avoidance of excessive drinking, concentrated and massy } \\
\text { foods and drinks, anything that causes excessive dryness, } \\
\text { anything that makes too much vapor, overeating, Vegetables } \\
\text { such as garlic, onion, chives, ripe olives, dill, cabbage and } \\
\text { lentils, eating too much sweets, eating foods that are hard to } \\
\text { digest, headache-inducing foods, sexual stimulants, eating } \\
\text { spicy and melancholy inducing foods, and eating different } \\
\text { foods in tandem. }\end{array}$ & $20-21-22$ \\
\hline & Weather & $\begin{array}{l}\text { Avoidance of smoke, steam, out of moderation weather (very } \\
\text { hot or cold), dusty and poisonous winds }\end{array}$ & $28-29-30-31$ \\
\hline & $\begin{array}{l}\text { Physical } \\
\text { activities \& } \\
\text { rest }\end{array}$ & $\begin{array}{l}\text { Avoidance of reading very small size transcripts and watching } \\
\text { very tiny objects, and continuous gaze to a single object. }\end{array}$ & $25-26-27$ \\
\hline & $\begin{array}{l}\text { Sleep \& } \\
\text { wakefulness }\end{array}$ & $\begin{array}{l}\text { Avoidance of long or short sleeping and wakefulness, sleeping } \\
\text { immediately after eating food, and sleep in the supine } \\
\text { position. }\end{array}$ & $23-24$ \\
\hline & $\begin{array}{l}\text { Evacuation \& } \\
\text { retention }\end{array}$ & $\begin{array}{l}\text { Avoidance of severe vomiting, successive venesection and } \\
\text { hijama, too much crying, excessive intercourse, and excessive } \\
\text { bathing. }\end{array}$ & $32-35$ \\
\hline & $\begin{array}{l}\text { Psychological } \\
\text { states }\end{array}$ & $\begin{array}{l}\text { The diseases and conditions that affect the health of the brain } \\
\text { such as emotional and psychological states affect the eye } \\
\text { health. }\end{array}$ & $33-34$ \\
\hline \multicolumn{2}{|c|}{$\begin{array}{l}\text { Useful points for } \\
\text { Eve health }\end{array}$} & $\begin{array}{l}\text { Pouring fennel juice in the eyes, pouring sweet or sweet and } \\
\text { sour pomegranate juice in the eyes, and opening eyes in the } \\
\text { water. }\end{array}$ & $36-37$ \\
\hline
\end{tabular}


Therefore regarding to mentioned studies, considering correct lifestyle is beneficial in eye health maintenance and prevention of its diseases.

\section{Conclusion}

Correct lifestyle in addition to improving the general health has an important role in eye health. By modifying lifestyle the risk of developing many eye disorders such as near-sightedness, age-related macular degeneration, glaucoma, and cataract can be reduced. More clinical studies should be performed to prove the role of all components of the six principles of health maintenance on eye health.

\section{References}

1. Shaharzani MA. Teb-e Akbari (persian) 1. Qom: Jalaloddin; 2007. p. 165.

2. Ebn Nafis, Ali Ben Abialhazm, Almujaz fi atTeb, research by Abdolkarim Alqarbavi, Cairo, Ministry of Charity, Majles Alala Leshouen Aleslamieh, 1986. P. 154.

3. Avicenna Al-Qanun fi at-Teb (Canon of Medicine). Beirut: Alaalami Library; 2005. Vol (2) pp. 354-97.

4. Naseri M, Jafari F, Alizadeh M. Principles of health maintenance in Traditional Iranian Medicine. Journal of Islamic and Iranian Traditional Medicine..44-39:(1) 1 ;2010

5. Khodaei MA, Ghaffari F, Emadi F, Emaratkar E, Alijaniha F, Noorbala AA et al. Healthy lifestyle in Prevention and Treatment of Depression from the View of Iranian Traditional Medicine. Medical History Journal. 2017;9(30):169-92.

6. Rezaeizadeh H, Alizadeh M, Naseri M, Ardakani MS. The traditional Iranian medicine point of view on health and disease. Iran J Public Health. 2009; 38(Suppl 1):169-72.

7. Hashemi H, Rezvan F, Yekta A, et al. The prevalence and causes of visual impairment and blindness in a rural population in the north of Iran. Iran J Public Health 2015; 44:855-64.

8. Rosenberg E. A., Sperazza L. C. The visually impaired patient. Am FAM Physician. 2008; 77:1431-6.

9. Mohammadi S-F, Saeedi-Anari G, Ashrafi E, Mohammadi S-M, Farzadfar F, Lashay A et al. Prevalence and major causes of visual impairment in Iranian adults: A systematic review. Middle East African journal of ophthalmology. 2017; 24(3):14855.

10. World Health Organization (WHO) Visual impairment and blindness. Fact Sheet No. 282, updated August 2014 (page on the Internet). c2014 (cited 2014 Aug 18). Available from: http:// www.who.int/mediacentre/factsheets/fs282/en/

11. Maake MM, Oduntan OA. Prevalence and causes of visual impairment in patients seen at Nkhensani Hospital Eye Clinic, South Africa. African journal of primary health care \& family medicine. 2015; 7
(1):1-6.

12. Cardarelli WJ, Smith RA. Managed care implications of age-related ocular conditions. The American journal of managed care. 2013; $19(5$ Suppl):S85-91.

13. Choopani R, Emtiazy M.The Concept of Lifestyle Factors, Based on the Teaching of Avicenna (Ibn Sina). Int J Prev Med. 2015; 6:30.

14. Rhazes. (Al- Havi the Continence), Translated by Zaker. Tehran: Shahid Beheshti University of Medical Sciences; 2015; 2:213-40.

15. Gilani M. Hefz al- Sehe Naseri. Traditional Iranian Medicine. 2011; 2:198-9.

16. Aghilli Mh. Makhzan al-adwiya. Tehran: : Tehran University of Medical Sciences; 2009.

17. Nafis I. Al-Shamel fi al-Sana'a al-tebiyeh. Tehran: Tehran University of Medical Science; 2008.

18. Moeini F, Jafarian AA, Kamalinejad M, Ale Taha N, Yazdian MA. Review of Stomach- Related Eye Diseases from Traditional Medicine Perspective. International Journal of Life Sciences. 2015; 9(2): 14-7.

19. Sharts-Hopoko NC. Lifestyle strategies for the prevention of vision loss. Holist Nurs Pract 2010; 24:284-91

20. Raman R, Vaghefi E, Braakhuis AJ. Food components and ocular pathophysiology: a critical appraisal of the role of oxidative mechanisms. Asia Pac J Clin Nutr. 2017; 26(4):572-85.

21. Bringmann A, Hollborn M, Kohen L, Wiedemann P.Intake of dietary salt and drinking water: Implications for the development of age-related macular degeneration. Mol Vis. 2016; 22:1437-54.

22. Klein BE, Klein R. Lifestyle Exposures and Eye Diseases in Adults. Am J Ophthalmol. 2007; 144 (6):961-9.

23. Ji Y, Li M, Zhang X, Peng Y, Wen F. Poor Sleep Quality Is the Risk Factor for Central Serous Chorioretinopathy. J Ophthalmol. 2018; 2018:9450297.

24. Li S, Ning K, Zhou J, Guo Y, Zhang H, Zhu Y, et al. Sleep deprivation disrupts the lacrimal system and induces dry eye disease. Exp Mol Med. 2018; 50(3): e451.

25. Gale J, Wells AP, Wilson G. Effects of Exercise on Ocular Physiology and Disease. Surv Ophthalmol. 2009; 54(3):349-55.

26. Knudtson MD, Klein R, Klein BE. Physical activity and the 15-year cumulative incidence of age-related macular degeneration: the Beaver Dam Eye Study. Br J Ophthalmol. 2006; 90(12):1461-3.

27. Theophanous C, Modjtahedi BS, Batech M, Marlin DS, Luong TQ, Fong DS. Myopia prevalence and risk factors in children. Clin Ophthalmol. 2018; 12:1581-7.

28. Ettl AR, Felber SR, Rainer J.Corneal Edema Induced by Cold. Ophthalmologica. 1992; 204 (3):113-4. 
29. Weale RA. Ethnicity and glaucoma: Higher environmental temperatures may accelerate the onset, and increase the prevalence, of primary open -angle glaucoma. Med Hypotheses. 2007; 69 (2):432-7.

30. West SK, Bates MN, Lee JS, Schaumberg DA, Lee DJ, Adair-Rohani $\mathrm{H}$, et al. Is Household Air Pollution a Risk Factor for Eye Disease? Int J Environ Res Public Health. 2013; 10(11):5378-98.

31. Perez-de-Arcelus M, Toledo E, Martinez-Gonzalez MA, Martin-Calvo N, Fernandez-Montero A, Moreno-Montanes J.Smoking and incidence of glaucoma. Medicine (Baltimore). 2017; 96 (1):e5761.

32. Qu W, Li Y, Song W, Zhou X, Kang Y, Yan L, et al. Prevalence and risk factors for angle-closure disease in a rural Northeast China population: a Population-based survey in Bin County, Harbin. Acta Ophthalmol. 2011; 89(6):e515-20.

33. Rubaie K, Arevalo F. Valsalva Retinopathy
Associated with Sexual Activity. Case Rep Med. 2014; 2014:524286.

34. Carrim ZI, Ahmed TY, Taguri AH. The relationship between stress and acute anterior uveitis. Acta Ophthalmol Scand. 2006; 84(6):7958.

35. Yilmaz U, Gokler ME, Unsal A.Dry eye disease and depression-anxiety-stress: A hospital-based case control study in Turkey. Pak J Med Sci. 2015; 31(3):626-31.

36. Hassan OA, Abu-Raghif AR, Rasheed AM, AlYawer MA. Effect of Foeniculum vulgare Seed Aqueous Extract Eye Drops on Selenite induced Cataract in Rabbits. Int. J. Pharm. Sci. Rev. Res. 2017; 47(1): 83-7.

37. Kamal NS, Gomaa AM, Aziz MA, Ebrahim NF, Ahmed SS. The protective effect of Punica granatum (pomegranate) against glaucoma development. Saudi J Health Sci. 2015; 4:171-8. 